\title{
Definiciones de la identidad del Uruguay durante el primer gobierno del Frente Amplio
}

\author{
Definitions of Uruguay's identity during \\ the first Frente Amplio government
}

\author{
Nastasia Barceló Severgnini ${ }^{*}$
}

\begin{abstract}
RESUMEN
Desde el proceso de redemocratización, Uruguay ha tenido que enfrentar diversos cambios en el sistema internacional, y más inmediatamente en el contexto económico y político regional, lo que ha derivado en la realización de sustanciales cambios en la política exterior del país. A partir del estudio de los principales cambios en materia de política externa, desde la apertura democrática (1985), con especial atención en los principios sobre los que se ha estructurado la política exterior desde inicios del s. xxI, más específicamente desde la asunción como gobierno de la coalición de partidos Frente Amplio (FA) en 2005, el presente trabajo analiza cuáles han sido los dilemas en materia de inserción internacional que Uruguay ha tenido que enfrentar y sus consecuencias. Para ello resulta fundamental identificar los roles y posturas de los principales decisores gubernamentales (eje Presidente, Ministro de Relaciones Exteriores, Servicio Exterior), así como las diferentes posturas al interior de la sociedad uruguaya en dicho período. En este sentido fue fundamental realizar un análisis crítico de la agenda vinculada a las negociaciones
\end{abstract}

\footnotetext{
Doctoranda en Ciencias por la Universidad de San Pablo. Magíster en Relaciones Internacionales por el Programa San Tiago Dantas. Licenciada en Relaciones Internacionales por la Universidad Federal de la Integración Latinoamericana. Trabaja principalmente en temas de historia de las relaciones internacionales de los siglos xix y xx y de política exterior de Uruguay y Brasil. Investigadora en el Laboratorio de Estudios sobre Brasil y el Sistema Mundial (LabMundi) de la usp. nastasiabsevergnini@gmail.com. Orcid:0000-0002-4385-8942.

Recibido: 23 de mayo de 2018. Modificado: 14 de febrero de 2020. Aceptado: 2 de marzo de 2020.
} 
comerciales con Estados Unidos durante el primer gobierno de Tabaré Vázquez (20052010). Para ello, me he basado en el análisis de fuentes primarias, es decir, documentos emitidos por órganos oficiales del Estado uruguayo así como de organismos regionales, principalmente el mercosur, y en fuentes de prensa del mismo período. Para tal efecto se empleó el abordaje constructivista de las Relaciones Internacionales, con el objetivo de identificar qué identidades estuvieron en debate y cual prevaleció. Las conclusiones señalan que Uruguay se debatió entre dos identidades estatales, la de miembro del mercosur, distante de Estados Unidos, y la de Estado no tan comprometido con el bloque regional y próximo a Estados Unidos, prevaleciendo la primera, aunque sin consolidarse plenamente, pues sobreviven condiciones tales que pueden reiniciar la discusión de identidad del país en el futuro.

Palabras clave: Política Externa - Uruguay - Inserción Internacional - MERCOSUR - Identidad - Partidos.

\section{ABSTRACT}

Since the process of redemocratization, Uruguay has had to face several changes in the international system, and more immediately in the regional economic and political context, which has led to substantial changes in the country's foreign policy. Based on the study of the main changes in foreign policy since the opening of democracy (1985), with special attention to the principles on which foreign policy has been structured since the beginning of the 21st century, more specifically since the Frente Amplio (FA) took office as government in 2005 , this paper analyses the dilemmas that Uruguay has had to face in terms of international insertion and their consequences. To this end, it is essential to identify the roles and positions of the main government decision-makers (President, Minister of Foreign Affairs, Foreign Service) as well as the different positions within Uruguayan society during that period. In this regard, it was essential to carry out a critical analysis of the agenda linked to the trade negotiations with the United States during the first government of Tabaré Vázquez (2005-2010). In order to do so, I based my analysis on primary sources, that is, documents issued by official bodies of the Uruguayan State as well as regional bodies, mainly MERCosur, and on journalistic sources from the same period. The constructivist approach of International Relations was used to identify which identities were under debate and which prevailed. The conclusions indicate that Uruguay was debated between two state identities, that of a 
member of MERCosur, distant from the United States, and that of a state not so committed to the regional bloc and close to the United States, with the former prevailing, although without fully consolidating itself, since conditions survive such that the discussion of the country's identity could be restarted in the future.

Keywords: Foreign Policy - Uruguay - International InsertionMERCOSUR - Identity - Parties.

\section{INTRODUCCIÓN}

El presente artículo tiene como tema la política exterior comercial desarrollada por la República Oriental del Uruguay con Estados Unidos de América en el período 2005-2010, el vínculo con el Mercado Común del Sur (MERcosur) y los posibles impactos que tendrían en la identidad internacional del Estado uruguayo.

Las negociaciones con Estados Unidos comenzaron en el período anterior de gobierno y resultaron en la firma del Tratado de Protección Recíproca de Inversiones (TPRI) a fines del año 2005, y en una serie de negociaciones sobre la firma de un Tratado de Libre Comercio (TLC) bilateral que se desarrollaron durante el año 2006 y condujeron finalmente a la firma de un Acuerdo Marco de Inversiones y Comercio (TIFA) en enero de 2007.
Cada una de las negociaciones implicó diversos grados de debates y presiones, que repercutieron a nivel doméstico, tanto en la sociedad civil organizada como en el gobierno uruguayo y, también, en los países miembros del mercosur. La magnitud de dichos debates, procesados a nivel doméstico e internacional, posibilita identificar un verdadero momento de potencial redefinición de la identidad del Estado uruguayo, lo que repercutiría en su política internacional a corto y mediano plazo. Por tratarse de una definición de identidad del país, se optará por analizar este período a la luz de una teoría apropiada para lidiar con cuestiones identitarias e ideacionales, como es el Constructivismo.

\section{IDENTIDAD: ENTRE CONSTRUCTIVISMO E HISTORIA}

Para el abordaje constructivista (Adler,1999; Checkel,1998, págs.325 a 338; Hopf,1998; Wendt, 1995; 1999; 2005), las relaciones entre agentes en el sistema internacional se enmarcan por medio de instituciones, es decir, identidades, intereses y expectativas establecidas mediante el proceso de interrelación 
entre ellos y del conocimiento compartido. Los agentes mantienen grados de autonomía y no son totalmente determinados por la estructura sistémica, no obstante esta orienta su actitud. El término para referirse a esta vinculación en que el agente crea la estructura pero esta también lo crea a él, lo moldea, es "co-constitución".

Una clase de institución que es formada mediante mecanismos de co-constitución son las identidades que representan y caracterizan a los agentes. La identidad —cómo él se concibe a sí mismo y cómo es visto por los demás - obedece, en parte, a su accionar, pero a eso se suma la percepción que tiene sobre cómo lo ven los otros miembros del sistema internacional, pues también en función de esa visión del "otro" se constituye la identidad propia. A este fenómeno por el que un agente asigna una identidad al otro y lo influye a adoptarla se lo conoce como altercasting (Checkel, 1998, págs. 325 a 338; Kratochwil, 2007, Págs. 506 a 511; Wendt, 1999; 2005).

Como agentes que son, los Estados como actores de las Relaciones Internacionales poseen identidades que establecen en su relación con los otros. Dichas identidades pueden ser difíciles de modificar, pero no son estáticas ni inmutables, sino que incluso a veces son la única variable que los pueden manipular (Wendt, 1999, pág. 21).

A la luz de la teoría, el debate que transitó Uruguay en ese período puede ser entendido como una fase de "planificación del personaje" y "autoreflexión crítica”, a la que hace referencia Wendt. ¿Pero cuándo y en qué condiciones se puede poner en práctica esta capacidad creativa? Se pregunta pertinentemente el autor:

La elección excepcional y consciente de transformar o de superar papeles necesita, al menos, dos precondiciones. Primera, tiene que haber una razón para pensar sobre uno mismo en nuevos términos; segunda, los costes esperados del cambio de papel internacional —las sanciones impuestas por aquellos con los que se interactuó con papeles anteriores - no pueden ser mayores que las recompensas (Wendt, 2005, pág. 28)

Este abordaje de las Relaciones Internacionales implica entender a la identidad del agente, en este caso sería la del Estado uruguayo, como una realidad en transformación, es decir, como un fenómeno esencialmente histórico. 


\section{PARTIDOS POLÍ́ticos y POlítica eXTERIOR EN URUguay: IDENTIDADES HISTÓRICAS DEL URUGUAY CONTEMPORÁNEO}

La identidad es una construcción histórica en transformación, que va sufriendo modificaciones, y a veces transformaciones que pueden ser analizadas mediante el lente del constructivismo. Dado que abordar la identidad de Uruguay a lo largo de toda historia escaparía a las posibilidades de este trabajo, me remitiré a las obras de intelectuales que han lidiado con esa problemática en tiempos distintos, a modo de exponer las ideas que moldearon las distintas concepciones identitarias más recurrentes del Uruguay Internacional.

Para comprender el caso uruguayo hay que partir de la idea de que su sistema político se caracteriza por la presencia de partidos fuertes, estables, arraigados en la ciudadanía y altamente disciplinados (Caetano et al., 1988; Buquet \& Chasquetti, 2004). Los partidos se estructuran en torno a fracciones altamente institucionalizadas y estructuras de liderazgo fuertes. Esto quiere decir que los posicionamientos de las fracciones en Uruguay tienen relevancia analítica. En materia de política exterior, la centralidad de partidos y sus respectivas fracciones ha sido destacada (López, 2015).

En 1959, Carlos Real de Azúa ${ }^{1}$, en su reconocida obra "Política Internacional e Ideologías en el Uruguay", refiriéndose a la política exterior del país entre 1939 a 1959, llega a la conclusión de que dos grandes visiones de política externa estarían en confrontación, una universalista, de carácter liberal-democrática, que apoya a los aliados y se alinea con su principal exponente, Estados Unidos, y otra de tipo resistente, que busca rescatar los valores regionales y la hermandad rioplatense y de la América Hispana. En relación a qué visión ha sido predominante, Real de Azúa (1959) plantea que en el período 19391959 fue la visión universalista. En tal sentido, Clemente (2010), en su análisis sobre el papel de Uruguay en las Conferencias Panamericanas, muestra cómo en el país se va consolidando una visión favorable a Estados Unidos, a medida que se producen sendos debates sobre los pasos a seguir y sobre el papel de Washington y su doctrina Monroe en América Latina. El Batllismo, sector político del Partido Colorado que dominó la política

1 Fue un "historiador latu sensu", pero también un ensayista de perfil sociológico, reconocido como uno de los precursores de la Ciencia Política uruguaya, pero también se lo reclama desde la crítica literaria, los estudios de Estética o desde el campo de las Relaciones Internacionales. En las palabras del Historiadaor y Politólogo Gerardo Caetano, fue un paradigma de los estudios interdisciplinarios. Para conocer vida y obra de Carlos Real de Azúa ver Caetano, Gerardo. Batthyány, Karina. (coords). Antología del Pensamiento Critico Uruguayo. - -1a ed.- Ciudad Autónoma de Buenos Aires: Clacso, 2018. Ximena Espeche, La paradoja uruguaya. Intelectuales, latinoamericanismo y nación a mediados del siglo xx. Bernal, Universidad Nacional de Quilmes, 2016. 
nacional a mediados del siglo xx, fue el responsable de llevar adelante esa política, mientras el Herrerismo, sector político dominante dentro del principal partido de oposición, el Partido Nacional, llevó adelante el posicionamiento resistente.

Como consecuencia de los posicionamientos de los diferentes Estados en la Segunda Guerra Mundial y de la posterior división impuesta por los grandes triunfadores, con la llamada Guerra Fría, en Uruguay surge una concepción autodenominada tercerista: con un asiento muy importante, aunque no exclusivo, en la izquierda nacional, en particular la Unión Popular y el Frente Amplio (FA), así como en círculos académicos, medios de prensa, y sectores organizados de trabajadores y estudiantes (Hernández Nilson, 2009). Hernández Nilson explica que el tercerismo es una corriente ideológica que conlleva una posición crítica:

Fue una visión de politica internacional representada por un grupo independiente: no clasificado en una ideología política definida, y sin pertenencia a un partido político nacional o a un movimiento ideológico internacional. El origen se asocia a un desprendimiento de la corriente resistente, en la medida que muchos de sus pensadores estuvieron vinculados a la figura del histórico líder del PN, Luis Alberto de Herrera (18731959): Alberto Methol Ferré, Carlos Quijano, Carlos Real de Azúa, entre otros. Su integración asoció, en forma más que laxa, facciones de centro, centroizquierda y hasta algunos grupos que se consideraron de extrema izquierda (Hernández Nilson; Fernández Luzuriaga, 2009, Pág. 12).

Dicha identidad partidaria está conformada por un conjunto de valores propios de la tradición de la izquierda uruguaya, algunos compartidos con los partidos tradicionales y otros enfatizados o distinguidos desde el progresismo. Entre dichos valores, Hernández Nilson y Fernández Luzuriaga (2009) identifican: el no alineamiento; el antiimperialismo; el anticolonialismo; la solución pacífica de controversias; el rechazo al terrorismo y muy especialmente al de Estado, la búsqueda del multilateralismo, desde una potenciación de la capacidad negociadora de los países en desarrollo y con énfasis en los procesos de integración latinoamericana; la cooperación internacional en todas sus manifestaciones, incluyendo la militar, y la vinculación con los uruguayos en el exterior. 


\section{LA POLIÍTICA EXTERIOR URUGUAYA DE LA REDEMOCRATIZACIÓN: PRINCIPALES CARACTERÍSTICAS}

El período descrito en esta sección abarca las administraciones de Julio María Sanguinetti (1985-1990) y Luis Alberto Lacalle (1990-1995). En el año 1985, Uruguay retornó a su institucionalidad democrática, período que estuvo caracterizado por las confrontaciones poder civil-poder militar por un lado y poder militar-sociedad civil, por el otro. La primera confrontación se produce por haberse obviado la pactada convocatoria a una Asamblea Constituyente en julio de 1985, que significó un rotundo rechazo a la institucionalización del Consejo de Seguridad Nacional y, en consecuencia, de la participación militar en el ejercicio del poder. La segunda confrontación dominó la escena política a lo largo del período (Fernández Luzuriaga, 2004, pág. 5).

Entre 1985 y 1990, el Partido Colorado ganó la Presidencia y obtuvo mayoría simple en el Poder Legislativo. En este período se gobernó con base en coaliciones débiles o acuerdos de gobernabilidad del partido mayoritario con el otro partido tradicional, panorama que se repite durante la Presidencia de Lacalle, entre 1990 y 1995.

De acuerdo a Carlos Luján, la agenda externa de esos años se estructuró a través de tres criterios, el primero sería el de círculos concéntricos, teniendo como epicentro a Uruguay, por lo que se establecen diferentes grados de cercanía; países de la subregión, región, hemisferio y resto del mundo.El segundo criterio es denominado por Luján como planos de relacionamiento, y establece que la agenda se articula mediante tres dimensiones: la cultural, política y económica. La dimensión cultural vincula al país en una triple pertenencia: Occidente, Hispanoamérica y Cono Sur.La dimensión política se refería a la participación de Uruguay en instancias de coordinación en organismos informales como el Grupo de Apoyo a Contadora y posterior Grupo de Rio, y en organismos formales como Naciones Unidas (ONU) y la Organización de Estados Americano (oea).

Uruguay formó parte del Grupo de Apoyo a Contadora. Esta política no es menor si tenemos en cuenta la historia reciente del país y la región, por aquellos años. Compuesto por Brasil, Argentina, Perú y Uruguay, en la práctica este grupo significó retomar una tradición latinoamericana de concertación política que había sido dejada de lado durante las décadas anteriores.

En la dimensión económica, el gobierno privilegió dos grandes ejes de acción; el económico-comercial multilateral, el país fue sede a la Ronda Uruguay del gatT y sancionó leyes que promovían el comercio y las inversiones (López Burián, 2015, pág. 185), y el económico-comercial subregional, 
mediante el acercamiento con Brasil y Argentina, clave para el futuro de la política exterior ${ }^{2}$. En este sentido, Fernández Luzuriaga (2004) señala que los principales mecanismos utilizados como vías de reactivación económica en la primera fase de la era democrática fueron los Acuerdos de Complementación Económica (ACE) con Argentina y Brasil, el Convenio Argentino-Uruguayo de Cooperación Económica (CAUCE) y el Protocolo de Expansión Comercial con Brasil. El paso siguiente fue en el mes de abril de 1988, cuando se subscribió el Acta de Alborada, por la que se abre la posibilidad de que Uruguay se afilie al joven proceso de integración iniciado por Argentina y Brasil. La integración, primero económica, era fundamental durante la redemocratización:

A determinação com que Alfonsin e Sarney trataram de promover a integração econômica entre os dois paises foi tanta que em apenas um ano se encontraram três vezes, duas com a participação do presidente do Uruguai, Julio Maria Sanguinetti (Bandeira, 2003, pág. 64).

En 1986 se llevó a cabo la reestructuración del Ministerio de Relaciones

2 Camilo López Burián (2015) destaca que en el ámbito regional, Uruguay adoptó dos estrategias durante el período: su incorporación al germinal proceso de integración de la subregión y la participación en procesos de concertación política en el ámbito latinoamericano.
Exteriores, que respetó la división en círculos concéntricos a través de la reorganización en Direcciones Regionales, a la vez que reorganizó las Direcciones Generales para Asuntos Económicos, Políticos y Culturales. La estructura orgánica de la Cancillería se complementa con otras Direcciones como Organismos Internacionales, Asuntos Limítrofes, Marítimos y Fronterizos. Los puntos de alta prioridad en la política externa de la redemocratización fueron la política subregional, las relaciones con Estados Unidos, las relaciones con los países de la Comunidad Europea ceE y las relaciones con los países socialistas, cuya orden de prioridad estaría determinada por el criterio de los círculos concéntricos (Luján, 2010).

A su vez hubo algunos temas que prevalecieron desde la agenda de la política externa de la etapa dictatorial a la agenda de la política externa de la democracia, pero que sin embargo experimentaron una serie de cambios en las políticas implementadas sobre esos asuntos. En las relaciones subregionales, se pasa de un enfoque de intereses geopolíticos a uno de cooperación con sus dos países limítrofes. Las relaciones con Europa Occidental cambian al dejarse a un lado las mutuas críticas a favor de una vinculación orientada a los esfuerzos de redemocratización. Durante todo el período se buscó restablecer relaciones con Europa Oriental y establecer relaciones con nuevos países. López (2015) entiende que el pragmatismo en política exterior fue 
una seña de identidad de esta estrategia: "El signo político de los países no pareció importar" (pág, 188).

Al igual que otros países de América Latina, Uruguay adolecía de un grave endeudamiento externo a la salida de la dictadura, situación que había adquirido una inusitada volatilidad por la elevación de las tasas de interés en Estados Unidos. En este sentido, la administración presidida por Sanguinetti rechazó las medidas más drásticas, como la moratoria y la adhesión al nunca materializado Club de Deudores. En este contexto, el gobierno uruguayo consiguió refinanciar gran parte de la deuda externa en el marco de la propuesta estadounidense del "Plan Brady", lo que le permitió disponer de fondos para su desarrollo. Es decir que en el plano financiero internacional, el país logró mejorar su posición.

Luis Alberto Lacalle fue electo presidente con el 38,9\% de los votos. El Partido Nacional gobernó en base a acuerdos con todos los sectores del partido colorado. La coalición construida adoptó el nombre de "Gobierno de Coincidencia Nacional" y formó su gabinete con ocho ministros del PN y cuatro del PC. Durante este período de gobierno, la Cancillería estuvo primero en manos de Héctor Gross Espiell, desde el 1o de marzo de 1990 al 4 de enero de 1993 y desde esta fecha al 1o de marzo de 1995, en manos de Sergio Abreu, también del PN (López, 2015).

En términos generales, durante este período también se amplía la agenda externa con temas como la Antártida, recursos marítimos y mayor acercamiento al espacio iberoamericano ( $\mathrm{Lu}-$ ján, 2010).

En la década del '90, los países latinoamericanos - bajo presión del FMI, del Banco Mundial y del gobierno de los Estados Unidos- fueron adhiriendo uno a uno al recetario del Consenso de Washington. Contradictoriamente, fue en ese período que avanzó el proceso de integración en el Cono Sur. Así, tras la firma del Tratado de Asunción de 1991 se funda el Mercosur. Sin embargo, la concreción formal del bloque significó un retroceso en relación a los acuerdos de 1986 y 1988, pues en lugar de la integración productiva prevista en los acuerdos comerciales, se privilegió la integración comercial; en lugar de la unión aduanera con protección externa a la producción regional, se practicó en "regionalismo abierto".

Ese proceso fue teorizado por la CEPAL. En un cambio en relación a su visión histórica, en la década de 1990 pasó a defender el "regionalismo abierto", que definía como:

(...) um processo de crescente interdependência no nivel regional promovida por acordos preferenciais de integração e por outras políticas, num contexto de liberalização e desregulação capaz de fortalecer a competitividade dos países da região e, na medida do possivel, constituir a formação de blocos para uma economia internacional mais aberta e transparente (CEPAL, 1994). 
Mucho se ha escrito sobre los motivos que dieron origen al bloque subregional, así como sobre el vínculo entre el regionalismo abierto y el neoliberalismo, sin embargo, lo que nos interesa en el presente trabajo es entender cómo fue la adhesión de Uruguay, sus principales motivaciones y los actores, en el ámbito doméstico del país, que influenciaron para su incorporación.

\section{LA INCORPORACIÓN DE URUGUAY AL MERCOSUR}

En el año 1985 se llevó a cabo la Conferencia Argentino-Brasileña de Foz de Iguazú, presidida por Raúl Alfonsín y José Sarney, marco histórico para un ambicioso proceso de integración entre las potencias regionales. Por su parte, Uruguay — presidido en ese entonces por Sanguinetti- siguió fielmente los distintos episodios de ese proceso, pero sin abandonar su postura de observador preocupado que el afianzamiento de las relaciones entre ambos vecinos no significase un deterioro de los compromisos comerciales asumidos a través del PEC y CAUCE (Peréz Antón, 2011).

En febrero de 1986 se celebró la primera reunión tripartita en la localidad uruguaya de Colonia, aquí se decidió que Uruguay adhiriese formalmente a los protocolos comerciales y de cooperación económica suscritos por Argentina y Brasil ese mismo año.En marzo de 1986 los especialistas en la materia comenzaron a negociar los términos materiales en los que se produciría la adhesión uruguaya, y ya durante el encuentro tripartito realizado en Brasilia, en abril del mismo año, se firmó el Acta de Alborada que sostiene lo siguiente:

Los Presidentes de la República Argentina y de la República Federativa del Brasil toman nota con satisfacción que la República Oriental del Uruguay comparte los enunciados generales y principios del procesos de integración argentino-brasileño. La participación del Uruguay se instrumentará de acuerdo con los grados y modalidades que las tres partes convendrán en cada caso, teniendo en cuenta las condiciones particulares del Uruguay y los instrumentos bilaterales vigentes con ambos países (Acta de Alborada, 1986).

El tercer encuentro trilateral se produjo en Buenos Aires en diciembre de 1986, con motivo de la firma del Tratado de Integración, Cooperación y Desarrollo entre Argentina y Brasil. $^{3}$ De esta manera es posible constatar cómo se fue procesando, en el

3 El encuentro realizado en la capital argentina motivó la elaboración de dos documentos sobre una eventual participación de Uruguay en una zona de libre comercio a instrumentarse en diez años. 
ámbito regional, la incorporación del país. En tanto, en el ámbito doméstico era posible identificar dos posiciones: la satisfacción de las autoridades gubernamentales por cómo ese iban procesando las demandas uruguayas, por un lado, y la inconformidad de algunos sectores al interior del país por la lentitud con que se llevaban las negociaciones, así como por el papel que desempeñaba el país en la integración.

En los años previos a la creación del mercosur, por medio de la Presidencia y de Cancillería, Uruguay se replanteaba sus relaciones bilaterales. Se restablecen relaciones diplomáticas con Venezuela y Cuba. También se restablecieron vínculos diplomáticos con China Popular, lo que a su vez implicó la ruptura de relaciones con Taiwán ${ }^{4}$. Si bien estos cambios constituyen un avance en la diversificación de las relaciones exteriores del país, Lincoln Bizzozero - en su trabajo Política Exterior y Actores en el Ingreso de Uruguay al Proceso de Integración Subregional - argumenta que el sistema político uruguayo no debatió en su debida dimensión los pro y contras del ingreso al MERcosur, porque ese proyecto se constituía en el único camino posible para la inserción del

4 En febrero de 1988 en un acto que el Canciller Enrique Iglesias denominó como Realismo Político Uruguay y China Popular restablecen relaciones, el proceso fue extenso y no exento de dificultades producida por presiones de la misma China y de Taiwán, así como de grupos económicos favorables a una y otra opción (Pérez Antón, 2011). país en el sistema internacional. En este sentido se identifica un déficit en la relación gobierno-sistema político, ya que el primero no propició las condiciones para que se produjeran debates en esa línea.

A mediados del año '90 se hicieron notar los avances en la integración argentino-brasileña, ahora en las administraciones de Menem y Collor de Mello. En esta dirección fue percibido que algún acuerdo comercial entre los dos grandes vecinos repercutiría en la actividad comercial amparada en el PeC y CaUce, Pérez Antón explica que:

Este factor sacudió la modorra de nuestro Servicio Exterior y los ámbitos de análisis y prospección de aquellas dos Secretarías de Estado. También consta que esa misma Cámara de Industrias, probablemente porque cumplía en algún grado el seguimiento regional que su Departamento de Estudios Económicos había recomendado en 1988, golpeó alarmada la puerta del Presidente Lacalle y le señaló dichas amenazas sobre el CAUCE y el PEC y tantos intereses exportadores públicos y privados (Pérez Antón, 2011).

En este contexto se pudo percibir una reacción rápida por parte del gobierno, es así que comienza a gestarse efectivamente el MERCosur. La adhesión al bloque contó con amplio respaldo de los diversos sectores políticos del país y de numerosos sectores sociales, pero también despertó algunos recelos, como el del Plenario 
Antisindical de Trabajadores Convención Nacional de Trabajadores (PITCNT), la Central Única de Trabajadores de Uruguay, que temía que los bajos precios de los productos de los países vecinos perjudicasen empresas y trajeran desempleo. Aún con esas preocupaciones, el Tratado fue ratificado por unanimidad en el Senado y con solo 2 votos contrarios en la Cámara de Diputados (Porzecanski, 2010, págs. 35 y 36, Pérez Antón, 2011, págs. 68 a 70).

Uruguay pretendía un ingreso en pie de igualdad a la negociación del Mercado Común, sin embargo, era un país que no aportaba un contenido demográfico relevante para un mercado que para esa época sumaba más de ciento cincuenta millones de habitantes, tampoco se añadían recursos estratégicos o escasos. Posteriormente, las resistencias al ingreso de Uruguay al MERcosur fueron superadas y desde el inicio el país asume la función de defensor del proceso y de su institucionalización.

Durante los años ' 90 el MERCosur aparece como el principal tema en la agenda de política externa, lo que conllevó a la reflexión sobre el rol de las Fuerzas Armadas. Hipotéticamente, la inserción en el MERCosur llevaría a la eliminación de posibles invasiones fronterizas, lo que sumado a la desaparición del conflicto bipolar, impulsó el debate sobre el papel de las FF.AA., que se procesó en dos ejes: mayor coordinación regional en la lucha contra el narcotráfico y contrabando, y un significativo incremento de la participación en Misiones de Paz de las Naciones Unidas, (Fernández Luzuriaga, 2004).

Se suele reconocer que los primeros años del mercosur fueron de un desempeño significativamente positivo, con un incremento del comercio y avances en materia de consolidación institucional del bloque (Bizzozero Reveles, 2010). En el aspecto comercial crecieron de manera exponencial los intercambios intrarregionales, y para Uruguay las exportaciones a la región oscilaron entre el 44 y el 56\%, mientras las importaciones desde los países de la región oscilaron entre el 43 y $47 \%$, lo que demuestra el grado de interconexión que el país llegó a tener con la región.

En el aspecto institucional, en los primeros años del Mercado Común proliferaron nuevos órganos y se consolidó la institucionalidad con la firma del Protocolo de Brasilia de 1991, que prevé un sistema provisorio de solución de controversias, y del Protocolo de Ouro Preto, en 1994, que consolidó la organización con el Consejo Mercado Común y el Grupo Mercado Común como principales órganos (Porzecanski, 2010). 


\section{LA POLÍTICA EXTERIOR DEL PRIMER GOBIERNO DEL FRENTE Amplio}

El triunfo electoral del Frente Amplio (FA) en el proceso electoral del año 2004, fue un hecho inédito en la historia de Uruguay, por cuanto la coalición de izquierda quebró 160 años de hegemonía de los partidos tradicionales en el gobierno. Sin necesidad de segunda vuelta, en octubre de ese año el FA obtuvo $50,45 \%$ de los votos válidamente emitidos en la elección, alcanzando la mayoría absoluta en el parlamento, lo que reflejaba el gran apoyo de la sociedad uruguaya al cambio y al proyecto político que traía consigo la izquierda. La mayoría en ambas cámaras posibilitó que se prescindiese de coaliciones interpartidarias, acuerdos de coparticipación que habían sido necesarios en las últimas administraciones.

En este período en la región sudamericana se produjo una coincidencia de aproximación ideológica entre los gobiernos electos. El Ministro de Relaciones Exteriores, Reynaldo Gargano, hacía referencia a la imagen de un arco virtuoso $^{5}$ con Lagos en Chile, Kirchner en Argentina, por Lula da Silva en Brasil, Vázquez en Uruguay, y Chávez en Venezuela, para describir la nueva realidad sudamericana ${ }^{6}$.

Los primeros contactos con los presidentes de estos países se produjeron en razón de la asunción del nuevo gobierno, el 1 de marzo de 2005. El 2 de marzo, Tabaré Vázquez se reunió con

$5 \quad$ La República, 1 de marzo de 2005. el Presidente argentino Néstor Kirchner, con quien dialogó sobre varios temas comerciales y políticos, augurando un buen relacionamiento entre ambos países (El País, 2005). Pocas horas más tarde el mandatario uruguayo se encontró con el Presidente brasilero Luis Inácio "Lula" da Silva para inaugurar una planta de la cervecera Ambev en la ciudad de Paysandú, ocasión en la que estuvo presente Eduardo Duhalde, presidente del Comité de Representantes Permanentes del mercosur. Allí se dialogó sobre el estado de mercosur, previéndose un futuro promisor al bloque por la convergencia ideológica de los gobiernos de sus países miembros, fortalecido por el ascenso de Vázquez (Vázquez y Lula; El País, 2005).

Las propuestas sobre política externa del FA estaban contendidas en el apartado Uruguay Integrado, parte clave del programa de gobierno, el cual enumeraba una clásica lista de principios como el no alineamiento con alianzas políticas o militares lideradas por grandes potencias, la defensa de los Derechos Humanos, el cumplimiento de buena fe de los tratados

6 El contexto regional trae consigo desafíos similares al período de la redemocratización de los años 80, en lo que se refiere a un cambio dentro del sistema político, a las relaciones de cooperación entre los países del subcontinente y a sus respectivos modelos de desarrollo. 
internacionales, la solidaridad internacional, el rechazo a todo tipo de terrorismo, violencia o discriminación. También postulaba al multilateralismo como la única forma de restablecer la plena vigencia del derecho internacional y la preservación de la paz (Fernández Luzuriaga, 2007).

El 11 de enero de 2005, el gobierno electo divulgó un documento denominado "Bases de Diálogo del FA" con los lineamientos generales que seguiría en Política Exterior, Economía y Educación. En materia internacional se plantea, entre otras cosas, la necesidad de consolidar el mercosur, pero también mantener o ampliar el acceso a mercados, dentro de los cuales menciona a Estados Unidos, condicionado a que no impacte negativamente al bloque (Documento; El País, 2005).La idea era iniciar conversaciones con el objetivo de crear acuerdos conjuntos en torno a esos tres temas. Luego de algunas conversaciones, sería aprobado por todos los partidos, con pocos cambios, el 16 de febrero de 2005 (El País, 2005).

En el momento que Vázquez llegó al poder priorizó sus relaciones con los socios del bloque, particularmente con Brasil y Argentina, preferencia que se expresaba en la estrategia adoptada por Uruguay como Más y mejor MERCosur. Para Vázquez era necesario implementar una amplia agenda que combinara integración económica y social:
En fin, vamos a decirles a nuestros hermanos argentinos, brasileños y paraguayos que las mujeres y los hombres de este país queremos más y mejor mercosur; (Tabaré Vázquez apud fRente amplio, 2004, Pág. 52) Consideramos importante decirlo en este ámbito, pues un acuerdo de este tipo [aludiendo al TPRI], negociado unilateralmente, significa un desconocimiento al MERCOSUR y a la necesidad de encarar estos temas como región (Tabaré Vázquez apud Frente Amplio, 2004, Pág. 54)

Sin embargo, algunos días después de su elección empezó a despertar la atención de la prensa el cambio de actitud de Vázquez en relación a la firma de un Tratado de Protección Recíproca de Inversiones con Estados Unidos: a lo largo de la campaña electoral Vázquez se mostró profundamente crítico al TPRI, no obstante tras su elección comenzó a expresar que el mismo debía ser estudiado y analizado, dejando de lado la anterior negativa categórica (Elección; El País, 2004). De esta manera, el 10 de noviembre de 2004 se reunió con el embajador de Estados Unidos en Uruguay, Martin Silverstein, con la finalidad de revisar el contenido del TPRI, quien plantea que eso sí era posible (El País, 2004)

No obstante, el tema del TPRI aparecerá constantemente en la agenda pública recién a fines de mayo de 2005 , cuando el senador de oposición por el 
Partido Nacional y ex Canciller, Sergio Abreu —en una entrevista radial cuestionó la actitud del gobierno de demorar la ratificación del acuerdo, identificando, hábilmente, una división de opiniones a favor y en contra de su ratificación en el partido de gobierno (Abreu; El País, 2005). A partir de entonces se produjo una serie de pronunciamientos, discursos, favorables y contrarios, que aglutinaban los más variados argumentos. La mayoría trataba de manera excluyente la alianza con Estados Unidos y la inserción de Uruguay en la región, más específicamente en el MERCosur.

Algunos días después del pronunciamiento de Abreu, se produjo un debate entre Alberto Curiel, Senador del Mpp, con el Ministro de Economía y Finanzas, Danilo Astori, pues el primero exigió que se informara a los demás miembros del bloque MERCOsUR sobre el contenido del TPRI así como el contenido de las negociaciones con Estados Unidos, ante lo que el ministro replicó que ni Argentina ni Brasil informan a Uruguay sobre sus medidas económicas (Mercosur; El País, 2005). Estas fueron las primeras reacciones al interior del sistema político uruguayo.

Vázquez llevó a cabo negociaciones con Estados Unidos con la intención de firmar un Tratado de Libre Comercio (TLC). Las mismas tienen inicio bajo la administración de Jorge Batlle, y ya en el gobierno del FA se produce la ratificación del TRPI, manifestando así el descontento con la carencia de propuestas para disminuir las asimetrías al interior del bloque.

Las expectativas que habían sido creadas en torno a la postura del nuevo gobierno eran, pues, de que no se acompañara la política de su predecesor y se rechazara el TPRI. No obstante, aconteció todo lo contrario, como fue señalado anteriormente. El cambio de postura por parte del gobierno comienza a delinearse en el documento de las negociaciones por las que el Frente Amplio buscó establecer consensos con los otros partidos políticos. Las "Bases de Diálogo del FA" planteaban:

La consolidación del MERCOSUR COadyuva a tales efectos y reafirmamos que consideramos a este proceso de integración subregional como una prioridad, [...]

El hecho de ser integrantes del Acuerdo regional no implica una limitación a la búsqueda constante, en forma individual, de acceso a mercados en donde el Uruguay pueda colocar su producción exportable.

Tal línea de acción deberá ser llevada adelante en la medida en que la misma no resulte violadora de los acuerdos establecidos en el marco del pacto regional (Bases de dialogo del FA; El País, 2005).

El texto expuesto permite destacar dos cosas; por un lado, es una clara apuesta a la integración; pero por otro, reconoce la posibilidad de negociar en temas comerciales con Estados Unidos. 
Aunque esta posibilidad queda supeditada a la prioridad del pacto regional, resulta ambiguo en cuanto a que negociaciones como el TPRI serían aceptables si se justifica que no impactan al bloque.

\section{A. El mapa político en las negociaciones del TPRI}

$\mathrm{Al}$ interior del gobierno era posible identificar posiciones a favor de la ratificación del TPRI, como el Ministro de Economía y Finanzas Danilo Astori, y en contra como la del Canciller Reynaldo Gargajo. Por su parte, el Presidente Vázquez también demostraría reconocer puntos débiles en el MerCosur, aunque - como fue señalado aquí- haciendo énfasis en la importancia de fortalecer y recuperar el MERCOSUR.

Entre los políticos de oposición, que en general apoyaron el TPRI, el senador Jorge Larrañaga mostró posturas bastante críticas al estado en que se encontraba el mercosur. En particular fue contrario a la idea de consultar a los demás miembros del bloque sobre el Tratado. Así, en la sesión del Senado - celebrada el 4 de agosto de 2005- expresaría que era un "disparate" consultar a los otros países del bloque, pues "no hay ninguna normativa que obligue a hacer esa consulta" (Larrañaga, 2005). El 30 de noviembre de ese mismo año, en otra sesión del Senado, luego de que ya estaba concluida la renegociación, expone irónicamente: "Cabe preguntar si estos cambios propuestos a Estados Unidos también se van a someter a consulta del MERCOSUR" (Larrañaga; El País, 2005).

Otra figura clave del gobierno, que fue a favor e incluso gestionó el acuerdo fue el Vicepresidente Rodolfo Nin Novoa. El 6 y 7 de setiembre viajó a Washington, donde se reunió con la Secretaria de Estado Condoleezza Rice para preparar una reunión que tendría Vázquez más adelante. Tan solo algunas horas después declaraba que creía que el TPRI estaría ratificado antes de fin de año, al tiempo que defendía su contenido y conveniencia para el país. También expresó que si los países del mercosur, avisados sobre el tema y conscientes de la posibilidad de negociar en conjunto con Estados Unidos, no se habían expresado aún, estaban dando rienda libre a Uruguay (El País, 2005). Pero esas declaraciones generaron asperezas al interior del FA, especialmente con Gargano, que afirmó ser el vocero de la postura oficial del gobierno, y sostuvo que el Tratado estaba en manos del parlamento (Gargano; El País, 2005).

De lo planteado hasta aquí se puede observar que los sectores políticos con mayor visibilidad y cargos de gobierno, incluso los que fueron contrarios al TPRI, en general no identificaron incompatibilidades graves entre dicho tratado y el mercosur. Otra fue la postura de sectores políticos minoritarios dentro del Frente Amplio (Movimiento 26 de marzo, Movimiento 20 de mayo, Corriente de Izquierda, Corriente por la Victoria del Pueblo, 
entre otros), del Partido Comunista del Uruguay (también parte del Frente Amplio y que tenía varios legisladores, entre ellos al senador Eduardo Lorier), y de las bases de la coalición gobernante. Estos sectores sí mantendrían una permanente oposición por cuestiones ideológicas, en cuanto a la defensa de la idea del antiimperialismo y de que el país no podía dar la espalda al bloque en que se encontraba (Porzecanski, 2010, págs. 92 a 114).

También cabe mencionar diversas manifestaciones populares y movilizaciones en este período. En las protestas por la Cumbre de las Américas, el tenor de los mensajes era de "Fachos asesinos", "Fuera Bush", "Muerte al capital”, entre otros (El País, 2005). Los detenidos en esa ocasión, luego condenados por delito de sedición, aún serían noticia por varios días, pues la organización Plenaria Paz y Justicia (de lucha por los Derechos Humanos) argumentaría que eran presos políticos, les darían apoyo legal y convocarían a varias movilizaciones, pidiendo su liberación (Brovetto, 2005).

Durante los debates parlamentarios del 21 y 27/28 de diciembre, nuevamente habría movilizaciones por esta temática, las cuales se dieron en los entornos al Palacio Legislativo, así como dentro en las "barras". Los presentes gritarían a los legisladores oficialistas términos como "traidores", "vende patria," "patria sí, colonia no", entre otras. No podemos olvidar, sin embargo, que todas estas movilizaciones congregaron a pocas personas. La organizada por el PIT-CNT durante la Cumbre contó con unos 1.500 participantes y aunque se trate de una estimación, lo seguro es que no se trató de un porcentaje significativo de la población. Ello no las hace menos importantes, pero deben ser consideradas con mesura. Tengamos presente también que no hubo movilizaciones públicas significativas a favor del TPRI.

Se puede identificar que los sectores políticos fueron en general bastante unánimes en defender el bloque como camino a seguir. Esto es así porque incluso quienes plantearon que el mercosur estaba en dificultades, como el Presidente, y aunque extrajeran de ello la conclusión de la necesidad de negociar con Estados Unidos u obtener otros socios económicos, defendían la necesidad de revitalizar y fortalecer el bloque, pues no identificaban una incompatibilidad entre la firma del TPRI con Estados Unidos y la pertenencia al mismo.

\section{B. Debates en torno a la firma de un TLC con Estados Unidos}

Pasadas las repercusiones de la firma del TPRI, el 5 de enero de 2006 el Ministro Astori anunció que el gobierno iniciaría negociaciones sobre un Tratado de Libre Comercio con Estados Unidos y China, pronunciamiento que fue desmentido por el Ministro Gargano pocos días después (Gargano; El País, 2006). Este cruce entre las autoridades de gobierno significó el inicio de un nuevo debate. 
La repercusión política a nivel regional no se hizo esperar. El 6 de enero el Canciller argentino Jorge Taiana criticó públicamente la posibilidad de un trc de Uruguay con Estados Unidos o China y, a su vez, afirmaba que entendía poco probable su realización (Argentina; El País, 2006). El 11 de enero, Celso Amorim, Canciller de Brasil, fue taxativo al declarar que sería impensable que un miembro del bloque establezca acuerdos comerciales de manera unilateral a menos que pretendiera salir del bloque (TLC; El País, 2006).

Ante un escenario de tensiones al interior del bloque mercosur, Gargano y la vice Canciller Belela Herrera brindaron conferencia de prensa el 12 de enero. En ella negaron que se negociara un TLC (Gargano; El País, 2006).

A pesar de las reacciones expresadas por los ministros de Brasil y Argentina, el 19 de enero el Presidente Kirchner, después de reunirse con Lula en Brasilia, brindó una conferencia de prensa para aclarar que ni Argentina ni Brasil se opondría a una negociación entre Uruguay y Estados Unidos para alcanzar un Tratado de Libre Comercio, ya que entendían que mercosur debía ser más flexible. Las declaraciones entraban en contradicción con las afirmaciones de Taiana y Amorim de unos días antes (MERcosur; El País, 2006).

A nivel doméstico se procesaron distintas posturas: dos ministros de gobierno como Héctor Lescano (de Turismo y Deportes) y Jorge Lepra (de Industria, Energía y Minería) se pronunciaron, rápidamente, favorables a la propuesta de Astori de negociar el TLC con Estados Unidos. Dentro del Partido Nacional emergieron voces como la de los senadores Sergio Abreu, Jorge Larrañaga y el diputado Álvaro Delgado, quienes se mostraron abiertos a cooperar con el Ministro de Economía.

El diputado colorado Washington Abdala también se pronunció favorable a la firma de un tratado de este tipo. Por otra parte, varios legisladores del Frente Amplio se declararon contrarios a iniciar tratativas, como es el caso del diputado del Movimiento de Participación Popular (MPP) Carlos Gamou, el senador Jorge Saravia de esa misma agrupación, el senador comunista Eduardo Lorier y la senadora socialista Mónica Xavier (Gargano; El País, 2006).

Después de conocer las posturas de los legisladores, el presidente Vázquez convocó a los principales líderes de la oposición a una reunión el día 30 de enero, con el objetivo de informarles que había encomendado al embajador uruguayo en Estados Unidos, Carlos Gianelli, que instrumente los mecanismos para ampliar las cuotas de importaciones de carnes, lácteos e informática, pero se negó a hablar de TLC (El País, 31/01/2006). En dicha ocasión el mandatario dio a entender que era favorable a iniciar negociaciones TLC con Estados Unidos.

Las distintas organizaciones de la sociedad civil también asumieron posturas favorables y contrarias, en 
relación al TLC. Entre las primeras destacan las de la Cámara de Industrias del Uruguay (ciu), la Asociación Rural del Uruguay (ARU), la Cámara Mercantil de Productos del País (CMpr) y la Cámara Nacional de Comercio y Servicios del Uruguay (CNCS) (Asociación
Rural del Uruguay et al. 2006). Entre las segundas, contrarias al acuerdo, el PIT-CNT, desde que trascendieron las declaraciones de Astori, dejó en claro su rechazo. Fue el sindicalista Marcelo Abdala, quien planteó que un TLC sería antiestratégico frente al MERCOSUR.

\section{Conclusiones}

La primera conclusión se refiere a la intensidad y los niveles en que se produjeron los debates vinculados a la política exterior en el período estudiado. Entre finales de 2004 y 2005, se concluye que el grado de discusión sobre la renegociación y ratificación del Tratado de Protección Recíproca de Inversiones fue intenso a nivel interno, pero a nivel de la relación microestructural, es decir con Estados Unidos y los países miembros del bloque MERCosur, no lo fue. La ausencia de un cuestionamiento concreto por parte de los socios comerciales del país incidió en que se reconociera la compatibilidad entre un acuerdo tipo TPRI y la identidad de Uruguay, y en este caso del propio Frente Amplio como miembro del bloque. Por su parte, el gobierno se preocupó por justificar dicha compatibilidad hacia otros actores de la sociedad civil y la opinión pública, que también estuvieron involucrados en el debate.

Por otro lado, cuando se llevó a cabo la discusión sobre la posible firma de Tratado de Libre Comercio emergería otra intensidad de debate que pasó a involucrar una impetuosa participación de Brasil y Argentina, en su calidad de miembros del MERCOSUR, presionando a Uruguay para no firmar el TLC y confirmar así su vocación integracionista, en un proceso de altercasting que abarcó distintas formas de coerción expresadas en la idea de flexibilizar el mercosur e incluso en la amenaza de tener que abandonar el bloque. A nivel doméstico, el debate generó el pronunciamiento de las burocracias estatales, condensadas en diversos informes técnicos que fueron difundidos en la prensa. La sociedad civil organizada también se expresó a través de las distintas organizaciones que tempranamente marcaron su postura. Sin embargo, tanto en las voces favorables y contrarias al TLC predominó la búsqueda de preservar la membresía plena del Uruguay en el bloque, los planteamientos de modificación del estatus dentro del mismo fueron la minoría.

Siguiendo el enfoque constructivista, es posible entender a aquellos años como un momento de "planificación del personaje” que implica modificar, 
parcialmente, la identidad del Estado en donde la percepción de una crisis al interior del bloque daría lugar a la condición de tener un motivo para pensar la identidad de un modo diferente, catalizada por la posibilidad de establecer acuerdos comerciales con Estados Unidos.

\section{Bibliografía}

Acuerdo Marco sobre Comercio e Inversión entre la República Oriental del Uruguay y los Estados Unidos de América (2007). Recuperado el 13 de noviembre de 2017 de http://archives.uruguay. usembassy.gov/usaweb/paginas/Pdf/ TIFA.pdf

Adler, E. (1994). "O construtivismo no estudo das relações internacionais”. Lua Nova $\mathrm{N}^{\circ}$ 47, diciembre, pp. 201-252

ARU (2006). Asociación Rural Del Uruguay et al. Posición conjunta respecto a la conveniencia para el Uruguay de negociar acuerdos comerciales con países de extrazona. Comunicado Conjunto. Recuperado el 2 de abril de 2020 de http://www.ciu.com.uy/innovaportal/v/684/24/innova.front/

Bandeira, L. (2004). As relações perigosas: Brasil-Estados Unidos (de Collor a Lula, 1990-2004). Rio de Janeiro: Civilização Brasileira.

Bandeira, L. (2003). Brasil, Argentina e Estados Unidos: conflito e integração na América do Sul. Da Tríplice Aliança ao Mercosul. Rio de Janeiro: Revan.

Bizzozero Reveléz, L. (2010), "Uruguay y los procesos de integración regional; trayectoria, cambios y debates", Civitas - Revista de Ciências Sociais, vol.10, núm.1, pp.97-117,
Bizzozero Reveléz, L. (S.F.) La inserción internacional de Uruguay en la globalización: una mirada multidimensional frente al nuevo siglo. Recuperado el 20 de octubre de 2018 de https://docplayer. es/63942209-Seminario-insercion-internacional-del-uruguay.html

Bouquet, D. y Chasquetti, D. (2004), "La democracia en Uruguay: una partidocracia de consenso". Política, núm. 42, pp. 221-247.

Caetano, G. y Rilla,J. (2004). “Los Partidos Políticos Uruguayos en el Siglo XX”, en El Uruguay del Siglo XX. Tomo II: La Polí tica. Colección dirigida por Benjamín Nahum. Montevideo: Ediciones de la Banda Oriental e Instituto de Ciencia Política. p. 15-64.

Caetano, G. y Batthyány, K. (cords). (2018). Antología del Pensamiento Critico Uruguayo. Ciudad Autónoma de Buenos Aires: CLACSO.

Cepal (1994). El regionalismo abierto en América Latina y el Caribe: la integración económica al servicio de la transformación productiva con equidad. Santiago de Chile. Recuperado el 2 de abril de 2020 de https://www.cepal. org/es/publicaciones/2140-regionalismo-abierto-america-latina-caribe-la-integracion-economica-al-servicio 
Checkel, J. (1998). "The Constructivist Turn in International Relations Theory”. World Politics vol. 50, No. 2. Jan. pp. 324-348.

Clemente, I. (2010). Uruguay en las conferencias panamericanas: la construcción de una opción en Política Exterior. los asuntos internacionales en América Latina y el Caribe: historia y teoría. Problemas a dos siglos de la emancipación Ponencia. [S.L.]

El País (2006). Argentina critica posible acuerdo comercial con EE.UU. Recuperado el 23 de enero de 2018 de http:// historico.elpais.com.uy/06/01/06/ultmo 194281.asp >

El País (2006). Amorim no apoya un TLC, Montevideo. Recuperado el el 23 octubre de $2017 \mathrm{de} \mathrm{http://historico.elpais.}$ com.uy/06/06/23/ultmo_223085.asp

El País (2006). Gargano negó negociación comercial con los EE.UU. Recuperado el 13 de octubre de 2018 de http:// historico.elpais.com.uy/06/01/07/pecono 194383.asp

El País (2006). Gobierno dividido por Estados Unidos. Recuperado el 17 de noviembre de 2017 de http://historico.elpais.com.uy/06/01/10/pnacio 194908.asp

El País (2006). Pit-Cnt: un acuerdo con EE.UU. sería desastroso. Recuperado el 18 de enero de 2019 de http://historico. elpais.com.uy/06/01/11/ultmo 195115.asp

El País (2006). Mayoría apoya el tratado de libre comercio. Recuperado el 21 de marzo de 2018 de http://historico.elpais. com.uy/06/03/23/pnacio_207727.asp

El País (2005). Abreu pide definición sobre tratado de inversión con EE.UU. Recuperado el 23 de noviembre 2017 de http://historico.elpais.com.uy/05/05/25/ ultmo_154569.asp

El País (2005). ARU afirma que el MERCOSUR “está mal”. Recuperado el 15 enero de $2018 \mathrm{de} \mathrm{http://historico.elpais.com.}$ uy/05/09/11/ultmo_173283.asp

El País (2005). Brovetto, los hechos del viernes y el 2002. Recuperado el 23 de noviembre 2017. http://historico.elpais. com.uy/05/11/08/pnacio_183824.asp>

El País (2005). Documento del gobierno electo llegó a Larrañaga, Sanguinetti y Mieres. Montevideo, 12 ene. 2005. Recuperado el 23 de noviembre de 2017 de http://historico.elpais.com.uy/05/01/12/ pnacio_131994.asp

El País (2005). Gargano critica declaraciones de Silverstein. Recuperado el 23 de octubre de 2019 de http://historico.elpais.com.uy/05/06/11/ultmo_157438.asp

El País (2005). Gargano sale al cruce de Nin por sus dichos sobre el tratado. Recuperado el 23 de enero de 2018 de http://historico.elpais.com.uy/05/09/08/ pnacio_172704.asp

El País (2005). Hoy firman documento de acuerdo. Recuperado el 17 de noviembre de 2017 de http://historico.elpais. com.uy/05/02/16/pnacio_138494.asp

El País (2005). Larrañaga: es un "disparate" esperar una posición de los países del MERCOSUR. Recuperado el 17 de marzo de 2018 de http://historico.elpais.com.uy/05/08/04/ultmo_166814.asp

El País (2004). Elección de Vázquez fortalece al MERCOSUR. El País, Montevideo, 08 nov. 2004. Recuperado el 15 de noviembre de 2017 de http://historico.elpais.com.uy/04/11/08/ ultmo 120715.asp 
El País (2004). Gobierno electo fortalecerá relaciones con EE.UU. buscando aumentar el comercio. Recuperado el 17 de noviembre de 2017 de http:/historico.elpais.com.uy/04/12/30/ ultmo_130007.asp

Ferro Clérico, L. (2006). Democracia y Política Exterior: Uruguay (1985-2006). América Latina Hoy, Montevideo, 44, 2006, pp. 115-132. Recuperado el 2 de abril de 2020 de https://www.researchgate.net/publication/26472230 Democracia_y_politica_exterior_Uruguay_1985-2006

Ferro Clérico, L.; Fernández Luzuriaga, W. y Hernández Nilson, D. (2006). La estrategia de inserción internacional de Uruguay en el gobierno del Frente Amplio. Revista Uruguaya de Ciencia Política. Montevideo. №15. 2006. pp. 129150. Recuperado el 2 de abril de 2020 de http://www.scielo.edu.uy/pdf/rucp/ v15n1/v15n1a07.pdf

Frente Amplio (2003). Grandes lineamientos programáticos para el gobierno 2005-2010. Porque entre todos otro Uruguay es posible. Montevideo: [s.n].19 p.

Guzzini, S. (2013). "Uma Reconstrução do Construtivismo nas Relações Internacionais".Monções: Revista de Relações Internacionais da UFGD, vol.2, №3, julio/ diciembre, pp. 38-51.

Hernández Nilson, D. y Luzuriaga, W. (2009). “Tradiciones Ideológicas de Política Exterior en las Propuestas Preelectorales 2009 de los Partidos Políticos Uruguayos”. Programa de Estudios
Internacionales de la Facultad de Ciencias Sociales de Universidad de la República.

Kratochwil, F. (2007). "Re-thinking the "inter" in International Politics". Millennium - Journal of International Studies, vol. 35, No3. Setiembre-Enero, pp. 495-511.

López, C. (2015). Partidos políticos y política exterior en Uruguay (1985-2015). La importancia de las instituciones, las ideas y los intereses de los actores. (Tesis de Doctorado en Ciencia Política). Universidad de la República.

Luján, C. (2010). “El caso uruguayo”, en Quiroga, F. (ed.), Consenso progresista. Política exterior de los gobiernos progresistas del Cono Sur: convergencias y desafíos. São Paulo: Fundación Friedrich Ebert, pp. 135-176.

Onuf, N. (2010). "Escavando a Comunidade Internacional: Por uma Arqueologia do Conhecimento Metafórico”.Contexto Internacional, vol. 32, №2. Julio-diciembre, pp. 253-296.

Onuf, N. (1994). "The Constitution of International Society”. EJIL, vol. 32, No8. Jul-Dec, pp.1-19.

Pérez Antón, R. (2011). Política Exterior Uruguaya del Siglo XX. Mondevideo: De la Plaza.

Porzecanski, R. (2010). No voy en tren. Uruguay y las perspectivas de un TLC con Estados Unidos (2000-2010). Montevideo: Random House Mondadori. 261 p.

Real De Azúa, C. (1959). Política Internacional e Ideologías en el Uruguay. Marcha No 966. Montevideo. 